\title{
Jóvenes y partidos políticos ¿una relación fracturada o definitivamente rota?
}

\author{
Youth and political parties: a fractured or definitely \\ broken relationship?
}

Natally Soria Moya*

Recepción: 1 de septiembre de 2019

Resumen

Aceptación: 25 de octubre de 2019

En las organizaciones políticas ecuatorianas existe una débil o mínima participación de jóvenes como militantes o como candidatos. Esto motiva la realización del presente estudio con seis partidos políticos nacionales para identificar su relación con los jóvenes. Además, también se convocó a jóvenes miembros de colectivos para entender por qué, si les interesa el trabajo social y el ejercicio de lo público, no pertenecen a los partidos.

Este estudio es un primer acercamiento a un tema que no ha sido estudiado en Ecuador: la relación de jóvenes y partidos políticos. A través de él, se puede comprender qué esperan los jóvenes de los partidos y viceversa, además de identificar como se caracterizan los unos a otros. Asimismo, a modo de conclusión, este estudio propone una serie de estrategias que podrían ayudar a los partidos a atraer más jóvenes a sus organizaciones.

Palabras claves: jóvenes, partidos políticos, movimientos políticos, representación, participación política, Ecuador.

\section{Abstract}

In general, participation of young people as militants or as candidates in Ecuadorian political organizations is weak or minimal. This affirmation motivates the realization of this research with six national political parties in Ecuador to identify their relationship with young people. In addition, this research includes interviews with young members of social groups to understand why if they are interested in social work, they don't belong to any political party.This research is a first approach to an issue that has not been studied in Ecuador: the relationship between youth and political parties. Through it, we can understand youth's demands of the parties and vice versa. Moreover, we can identify how they characterize each other. As part of the conclusions, this research proposes strategies that could help parties attract more youth to their organizations.

Key words: Youth, political parties, political movements, representation, political participation, Ecuador.

* Cabe mencionar la participación de Ismael Jaramillo, funcionario del Intituto de la Democracia, como asistente de investigación. 


\section{Introducción}

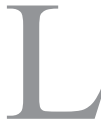

uego de 40 años de democracia, los partidos y movimientos políticos, el sistema de partidos y el sistema electoral ecuatoriano han ido modificándose para adaptarse a los poderes políticos, a las estructuras de poder, a los escenarios económicos y a las coyunturas.

En ese ir y venir de la política ecuatoriana, las organizaciones políticas no han dejado de ser las instituciones a través de las que se canaliza la participación y la representación, en términos formales; hecho que no corresponde a un mérito de las organizaciones políticas sino a que en Ecuador, el único mecanismo para participar en las elecciones, y así acceder a espacios de decisión, es un partido o movimiento político. Por esta razón, era importante preguntarse si las organizaciones políticas siguen siendo el mecanismo óptimo de representación y participación para la ciudadanía ecuatoriana.

Desde 2012, el Instituto de la Democracia, una entidad adscrita al Consejo Nacional Electoral, que tiene como funciones la investigación, capacitación y promoción político electoral, trabaja de cerca con todas las organizaciones políticas del país. A raíz de ese trabajo se ha evidenciado una particular ausencia de jóvenes en sus cuadros, en sus estructuras partidarias, en su militancia, en sus capacitaciones, eventos, y actividades.

Cuando hablamos de jóvenes, en este trabajo, nos referimos a todos aquellos comprendidos entre 16 y 35 años. Segmentación realizada considerando que en Ecuador el voto es facultativo para las personas comprendidas entre 16 y 17 años, obligatorio de 18 años a 65 años, y que 35 años es la edad mínima para ser presidente de la República - máximo cargo de elección popular-.

Con esta segmentación no se está asegurando que el comportamiento de todos los jóvenes comprendidos en este rango etario sea el mismo. Sobre cada uno no solo puede influir su edad, también su ubicación geográfica, sus características socioeconómicas, sus actividades profesionales, su formación académica, etcétera. Por eso, es importante aclarar que este es un primer acercamiento a la problemática para explicar la ausencia de jóvenes 
participando en política a través de organizaciones políticas, ya sea como candidatos o militantes.

La explicación de esa ausencia, según los directivos de las organizaciones políticas nacionales entrevistados, es que los jóvenes no están interesados en la política, que son egoístas y hasta individualistas. Asegurando, entonces, que el problema son los jóvenes que no tienen interés en participar, y no ellos como organización.

Frente a esta posición de las organizaciones políticas, era importante indagar ¿Por qué los jóvenes no acuden a los partidos y movimientos políticos? ¿Son las organizaciones políticas el mecanismo de representación que los jóvenes quieren y esperan? ¿Los partidos se han adaptado a sus nuevos electores y sus agendas? ¿Saben los partidos lo que quieren o piensan las nuevas generaciones?

Si los partidos políticos mantienen su posición en términos de "a los jóvenes no les interesa la política”, es probable que el resultado sea menos candidatos y militantes jóvenes. Incluso, lo más problemático sería que las organizaciones políticas no establezcan mecanismos o estrategias para incorporar jóvenes a sus estructuras.

Si sumamos a esto que el sistema electoral ecuatoriano permite candidatear no militantes o no adherentes, la formación de cuadros, que debería ser prioridad, puede pasar a segundo plano. La evidencia de esto es que una gran mayoría de los candidatos que encabezan listas no son militantes ni adherentes permanentes sino figuras de pantalla, deportivas, o actores políticos o dirigentes sociales locales.

Lo contradictorio es que cuando se dialoga con organizaciones de la sociedad civil, la postura difiere a la de las organizaciones políticas. Ellos aseguran que los jóvenes sí quieren participar de la política, solo que no desde los partidos. El problema con esto es que, si bien el activismo es importante, incluso puede incidir en agendas nacionales y/o internacionales, la realidad es que los partidos siguen siendo el único mecanismo para acceder al poder y la toma de decisiones. Como dice Bryce, no ha existido ningún país libre sin partidos, y nadie ha demostrado cómo podría funcionar el gobierno 
representativo sin ellos (Bryce en Montero et al. 2007).

Si los jóvenes, las organizaciones políticas y la sociedad civil se quedan en el simplismo/reduccionismo de aceptar estos argumentos como verdades absolutas, el futuro de la democracia, la política y los partidos está en peligro. Además de que, si los jóvenes se alejan de los partidos, se están alejando del poder y por ende pierden espacios para participar de la toma de decisiones.

Este escenario justifica el presente estudio que tiene como objetivo determinar si la relación entre jóvenes y partidos esta fracturada o definitivamente rota; $y$, a modo de conclusiones, sugerir algunas estrategias para replantear dicha relación y reconectar a estos dos actores fundamentales para el desarrollo de la democracia.

Para ello, en esta investigación se caracterizó el comportamiento de los jóvenes frente a la participación y la representación. También se indagó sobre la crisis o declive del sistema de partidos en Ecuador, como una posible explicación de la desconexión entre jóvenes y partidos.

Además, a fin de obtener información directamente de los actores involucrados, se realizaron reuniones con seis organizaciones políticas nacionales (CREO, Sociedad Patriótica, Partido Socialista, Izquierda Democrática, Alianza PAIS, Pachakutik). En éstas se entrevistaron a militantes y candidatos jóvenes y a directivos, por separado. El objetivo de estas reuniones fue determinar ¿cuál era su motivación para ser parte de la organización política?, ¿de qué manera están involucrados?, ¿qué tareas cumplen?, ¿cuánto tardan en visibilizarse políticamente?

También, se realizaron entrevistas a jóvenes que representan a diversos colectivos de la sociedad civil (sociales, artísticos, vinculados a temáticas ambientales, etcétera) para entender ¿por qué si les interesa el servicio público y el trabajo social prefieren no hacerlo desde una organización política?

Los resultados, si bien no pueden generalizarse a todos los jóvenes y mucho menos a todas las organizaciones políticas, permitieron repensar aquella premisa de que "a los jóvenes no les interesa la política", y plantear a modo de conclusiones, estrategias para atraerlos e involucrarlos. 
Este estudio era urgente y necesario, considerando que en el año 2021 se celebrarán elecciones generales en Ecuador y se espera que más jóvenes con preparación y convicción política participen como candidatos y que, incluso, ganen. Además, porque luego de la década presidencial de Rafael Correa (2006-2017), con un sistema concentrador de poder, los demás partidos y movimientos políticos intentan retomar su presencia nacional y local, lo que se evidencia en el hecho de que en las últimas elecciones seccionales 2019 participaron más de 81.000 candidatos, y para ello necesitan fortalecerse.

Ese proceso de fortalecimiento implica dejar de cargar toda la responsabilidad del desencuentro entre jóvenes y partidos en los mismos jóvenes, para intentar buscar respuestas en los partidos, en el concepto de ciudadano, en la educación cívica, en la concepción de la participación y la representación, así como, en los valores políticos.

Recalcamos que este es un primer acercamiento para explorar la dinámica de los jóvenes ecuatorianos, y para entender a los partidos. Esperamos, este artículo sea la motivación para más investigaciones que aborden y profundicen en variables no solo etarias, sino también sexogenéricas, sociales, y económicas. Es urgente y necesario encontrar mecanismos para vincular activamente a los jóvenes en política y en la toma de decisiones, no solo desde la sociedad civil, sino desde otros espacios de poder. En resumen, los partidos necesitan renovarse y sin los jóvenes será imposible.

\section{Jóvenes y ¿crisis de participación política?}

Cabe empezar mencionando que no existe bibliografía específica sobre jóvenes y partidos en Ecuador, por lo que los estudios citados responden a otros contextos y realidades que se asemejan a la realidad ecuatoriana y que permiten diagramar al menos un escenario general para entender la realidad nacional.

Considerando esto, es importante puntualizar, también, que la desafección política o la baja participación (en la toma de decisiones y en organizaciones sociales o políticas ya sea como candidatos o militantes) no es 
exclusiva de jóvenes ni de todos los jóvenes, sino que es un tema que abarca a gran parte de la sociedad ecuatoriana.

Esta afirmación, puede hacerse tomando el informe "Cultura política de la democracia en Ecuador y en las Américas, 2014", donde se establece que solo un $13.1 \%$ de los entrevistados ecuatorianos había participado de una reunión municipal (Donoso et al. 2015). Este dato es relevante para entender el comportamiento del ciudadano ecuatoriano frente a la participación, considerando que la intervención en lo local tiende a ser mayor que la nacional, y aun así es baja, lo que refleja que la no participación en la toma de decisiones es ajena a la edad.

Para tratar de explicar esta baja participación política, que parece ser una tendencia en América Latina, hay dos posiciones conceptuales. Están los que hablan de crisis de la participación y representación. Es decir, que existen ciudadanos que no consideran que la participación sea un mecanismo efectivo o de incidencia política o social; y/o que no se sienten representados por la clase política, y por lo tanto, no participan. Por otro lado, están los que explican la baja participación política como un proceso de transformación de la relación entre los ciudadanos con los mecanismos tradicionales de participación, o con los representantes, instituciones y organizaciones. Como parte del estudio empírico realizado se podrá observar, más adelante, que la tendencia es que los adultos se apeguen a la teoría de la crisis de participación y representación, y que los jóvenes hablen de transformación de relaciones.

Los que hablan de crisis argumentan que muchas sociedades estarían experimentando un fuerte declive del compromiso cívico, provocando una preocupante desafección democrática y un alarmante capital social que cada vez es más frágil; proceso que presenta síntomas y que Zubero (2003:29) enumera de esta manera: "a) salvo en coyunturas de fuerte tensión social o política, los niveles de abstención son elevados; b) la afiliación a partidos y a sindicatos, es irrisoria; c) la implicación de los escasos afiliados en la vida interna de los partidos es aún menor; d) aumenta la desconfianza hacia los dirigentes políticos, las instituciones políticas y, en general, hacia el proceso democrático; e) los partidos se profesionalizan, transformándose en auténticas industrias políticas". Estos "síntomas" son visibles en Latinoamérica y, en el 
caso ecuatoriano, de manera aún más evidente, en los jóvenes.

Por ejemplo, respecto a la confianza en las instituciones democráticas, según el informe "Cultura política de la democracia en Ecuador y en las Américas, 2016/7" los partidos políticos ecuatorianos tan solo tienen 20.3 puntos, siendo la institución con menor confianza en el país (Donoso et al. 2018:22). Esta situación de alguna manera explicaría por qué la sociedad ecuatoriana en general, y en especial, los jóvenes, no se sienten motivados a participar de una institución de la que desconfían.

En esa línea, Ramoneda (1999), indicaría que los tiempos de la pasión política han quedado atrás y hoy, más bien, estaríamos viviendo un tiempo de indiferencia, de una creciente desvalorización de lo público y, en consecuencia, de la despolitización de la vida social (Benedicto y Reinares 1992). Esto, como se observará en los resultados de las entrevistas, para los directivos de las organizaciones políticas, estaría asociado a los jóvenes, quienes argumentan que los jóvenes no tienen espíritu cívico, desconociendo el hecho de que los jóvenes de hoy (16 a 35 años) no vivieron ningún proceso histórico o político que pudiese haber fortalecido dicho espíritu cívico.

Este comportamiento es muy similar a lo ocurrido en países como Chile en donde la caracterización de los jóvenes iba cambiando acorde al momento histórico y político. Por ejemplo, en los 60 y 70, eran jóvenes universitarios de la reforma; en los 80, jóvenes pobladores de las protestas, y en los 90 , jóvenes genéricos problema (Cottet 1994: 306-309). Luego, dado que a medida que transcurrían los primeros años de la democracia, y los nuevos jóvenes no se inscribían en los registros electorales, se instaló el discurso del no están ni ahí: metáfora de una desvinculación formal con la política, la cual fue construida desde el adultocentrismo, que menosprecia o disminuye el rol de los jóvenes en la política actual por no haber experimentado la política

1. Adultocentrismo: categoría pre-moderna que designa en nuestras sociedades una relación asimétrica y tensional de poder entre los adultos (+) y los jóvenes (-). Esta visión del mundo está montada sobre un universo simbólico y un orden de valores propio de la concepción patriarcal. En este orden, el criterio biológico subordina o excluye a los jóvenes por la edad. Se traduce en las prácticas sociales que sustentan la representación de los adultos como un modelo acabado al que se aspira para el cumplimiento de las tareas sociales y la productividad (Krauskopf 2013). 
que a los adultos les tocó vivir durante su juventud y por no ejercer la política desde los espacios o mecanismos que ellos utilizaron.

Esta posición podría apoyarse en cifras como las de la Primera Encuesta Nacional sobre Jóvenes y Participación Política en Ecuador (2011: 17) que arroja que el 15,2\% de los jóvenes encuestados (16 a 29 años) a nivel nacional, en Ecuador, confiesan estar muy interesados por la política, mientras que el $14,2 \%$ señala que las cuestiones políticas no les concitan ninguna atención. Por otro lado, un $29,2 \%$ declara tener cierto interés en la política y otro $41,2 \%$ que le interesa poco. Si nos concentramos en estos datos, se evidencia que la desafección política en los jóvenes alcanza números altos. Pero si estas cifras se compara con los datos de la Primera Encuesta Nacional de Participación Ciudadana (2008), realizada a ecuatorianos entre 26 y 55 años, que arrojó que el $25,3 \%$ declara no tener ningún interés en la política y solo el 10,6\% está muy interesada, se podría decir que la desafección política es grave a nivel de toda la sociedad ecuatoriana. Lo que evidenciaría lo mencionado inicialmente, que esto no es un tema de jóvenes sino de toda la sociedad. Esta comparación entre jóvenes y adultos puede observarse en la siguiente Tabla.

\section{Tabla 1.}

Comparación entre jóvenes (16 a 29 años) y adultos (26 a 55 años) respecto a su interés por la política

\begin{tabular}{|l|c|c|}
\hline \multicolumn{1}{|c|}{ Interés por la política } & Jóvenes (2011) & Adultos (2008) \\
\hline Mucho & $15,2 \%$ & $10,6 \%$ \\
\hline Algo & $29,2 \%$ & $31,1 \%$ \\
\hline Poco & $41,2 \%$ & $32,8 \%$ \\
\hline Nada & $14,2 \%$ & $25,3 \%$ \\
\hline No responde & $0,2 \%$ & $0,2 \%$ \\
\hline N. de casos & 4.249 & 14.938 \\
\hline
\end{tabular}

Elaboración: ENPJ, Ágora Democrática (IDEA-NIMD)/Canadá, 2011

Fuente: EPNC-INEC-SENPLADES, 2008. 
Frente a esto, quienes hablan de transformación de la participación y representación tienen sus propios argumentos. Bianchi, León y Perini (2017) en su libro "Transformaciones de la participación política en América Latina", argumentan que lo que ocurre en realidad es una profunda transformación de la relación ciudadana con las estructuras y formas de participación tradicionales. En la mayoría de los casos éstas se ven sometidas a una fuerte crítica; pero, al mismo tiempo, surgen nuevas formas de acción colectiva no institucionalizadas.

Estas formas, según Puyosa, tienen características propias e incluso pueden llegar a constituirse en movimientos sociales: "1) Arranque emocional de la movilización y elaboración de marcos de injusticia, 2) Uso intensivo de plataformas tecnológicas para la interconexión entre actores, 3 ) Construcción de comunidades a partir de la creación de símbolos propios y lenguajes comunes, 4) Debates sobre temas y valores en espacios comunes deliberativos, 5) Carácter difuso del esquema organizativo de la estructura del movimiento y capacidad de interacción con semejantes, 6) Dinámicas de capital social que relacionan vínculos fuertes y débiles, 7) Acción colectiva para la ocupación de espacios públicos, 8) Acción Política contra hegemónica, 9) Conformación de redes limitadas en tamaño, 10) Propagación de ideas por difusión en cascada o contagio en redes" (2015: 201). Lo que explicaría por qué los jóvenes se involucran en política a través de colectivos $\mathrm{u}$ organizaciones de la sociedad civil y no a través de partidos.

Es, incluso, paradójico que se hable de un debilitamiento de la participación política de los jóvenes en el momento en que tienen más posibilidades de participar, protestar y exigir derechos. Por ejemplo, en el Ecuador el voto es facultativo desde los 16 hasta los 17 años y un joven desde los 18 años ya puede ser candidato y hasta autoridad electa. Además, se han dado grandes marchas internacionales, como las de Porto Alegre, encabezadas por jóvenes líderes donde miles de activistas inauguraron el Foro Social, el mayor evento de los movimientos sociales del planeta, con una marcha contra el capitalismo.

Entonces, es probable que el error esté en que la ciencia sigue tratando de explicar la participación política y en especial la de jóvenes, a través de 
estándares caducos. Probablemente estamos frente a una sociedad, y en especial frente a una generación de jóvenes, que rechaza la política tradicional pero que no es apolítica. De hecho, según los datos de la Primera Encuesta Nacional sobre Jóvenes y Participación Política en Ecuador (2011:22), un $12 \%$ de los jóvenes encuestados admite hablar de política de manera asidua (siempre y con frecuencia) y lo más interesante es que el $15,2 \%$ lo hace con los amigos y el 13,3\% con el padre. Lo que significa que existe un grupo de jóvenes que interactúa con otros jóvenes alrededor de la política. A estos chicos, Wilkinson los llamaría "hijos de la libertad", que no son más que todos aquellos jóvenes que huyen de toda participación que suponga imposición o coerción (Beck 1999:90).

Para Beck (1997) esto es la construcción de una nueva dimensión de lo político. Según él, lo político se manifiesta al margen del sistema político formal, en un terreno que denomina subpolítica. Espacio donde se plantean las grandes cuestiones del futuro, que no han nacido de los gobernantes ni de luchas parlamentarias. Si es así, la participación no está en crisis, lo que estaría en crisis es la manera de entender esa participación.

Por eso, Subirats (2011) dice que la gente se está adaptando a los cambios mejor que las instituciones y los partidos. Porque lo cierto es que la gente busca nuevos 'nosotros' en los que reconocerse. Y esto pasa mucho en los jóvenes, puesto que para ellos el reconocimiento en el otro supera incluso imperativos territoriales en las que los jóvenes se incorporan a comunidades transnacionales, pues perciben intereses comunes con jóvenes de diferentes geografías (Balardini 2000). De esta forma, emergen otras maneras de estar juntos; otros lenguajes y códigos simbólicos posibles gracias a las mediaciones tecnológicas (Agudelo, et al. 2013).

Estas características tienden a encontrarse en organizaciones menos rígidas, más abiertas, que aceptan pertenencias múltiples sin problemas, de lazos débiles, que se acomodan a las identidades parciales porque han nacido y crecido con ellas.

Concepción que coincide con un estudio realizado en Colombia sobre jóvenes y partidos que concluye que existe un grupo de jóvenes con 
mentalidad transformadora actuando y participando desde otros espacios distintos a los partidos. "Se trata de jóvenes que tienen una visión muy positiva sobre sí mismos, reconocen los valores y las concepciones que los caracterizan como líderes, como agentes de cambio en sus contextos, como sujetos políticos" (Agudelo, et al. 2013: 599).

Ante eso, el debilitamiento de la participación de los jóvenes no sería responsabilidad de ellos sino de las instituciones. Los jóvenes participan, pero bajo otros modelos. Como dice Worms (2003) "los jóvenes no se dedican a las mismas asociaciones que sus mayores, y tampoco lo hacen de la misma manera. Sus mayores ignoran o malinterpretan sus formas de participación" (Putnam 2003:301).

Por ello, según los datos de la Primera Encuesta Nacional sobre Jóvenes y Participación Política en Ecuador (2011), el 69,8\% de hombres jóvenes y el 77,4\% de mujeres jóvenes rechazan la idea de militar en partidos o movimientos políticos. Un alto porcentaje que evidencia que los partidos políticos no son atractivos para los jóvenes.

Sus razones giran en torno a no me gusta o no me agrada (46,9\%), no me interesa $(16,8 \%)$, hay peleas y desacuerdos $(9,6 \%)$, tengo desconfianza, hay corrupción $(8,4 \%)$, y no tengo tiempo $(7,6 \%)$. Lo del tiempo también se evidencia más adelante como una limitante para la participación política. Sin embargo, lo más importante es determinar por qué no les gustan los partidos, a fin de saber si sus motivos son negociables con los partidos o irreconciliables.

En ese sentido, es necesario reconocer que la participación no se agota en procedimientos de democracia representativa, que en Latinoamérica tiende a ser delegativa -en términos de O'Donell (2007)-. De hecho, es probable que ese delegacionismo sea la base de la creciente desafección por la política y la apatía ciudadana. Cuando se plantea la democracia participativa, se crean mecanismos que medien entre los ciudadanos y los tomadores de decisiones: referéndum, consulta popular, iniciativas populares parlamentarias, silla vacía, etc. Pero la realidad es que, según las encuestas analizadas, el ciudadano promedio no se siente parte de la toma de decisiones y considera que la política sigue siendo compleja y de élites; excluyente o un privilegio. 
Incluso, así lo describen los jóvenes entrevistados más adelante. Frente a ello, las instituciones, incluidos los partidos, deben aprender a escuchar y, sobre todo, a demostrar que escuchan (Ovejero 2003).

El interés por la participación política tiene mucho que ver con la manera en que la actividad política llega a la ciudadanía. Una sociedad en la que se vuelven comunes frases como: "yo no entiendo de política", "yo no me meto en política", "la política no me interesa", es una sociedad cívicamente enferma. Estas expresiones indican que las cuestiones políticas son percibidas como ajenas, lo que es un error. La política no solo es lo que hacen los políticos, sino está inmersa en todas las relaciones humanas, desde la familia, la escuela, los amigos. Es participar de la toma de decisiones para encontrar soluciones a los problemas. Ese debería ser el objetivo de cualquier gobierno (nacional o local), incentivar la participación de las personas a través del reconocimiento de los procesos participativos como habituales y cotidianos.

En ese sentido, la baja participación e interés en política no sería culpa de los jóvenes, ya que, a diferencia de generaciones anteriores, no han sido expuestos a la política en su etapa de crecimiento, por lo tanto, están menos informados sobre esta, lo que a la luz de su experiencia hace comprensible sus bajas tasas de participación (Wattenberg 2003).

Por lo tanto, el desinterés es, casi siempre, consecuencia de una política alejada, en el fondo o en las formas, de las preocupaciones ciudadanas. Y si se busca acercar la política a la ciudadanía y a los jóvenes hay que conectar la acción política con sus intereses. Por eso, Jáuregui, dice "la cesión de [los asuntos públicos] a favor de las élites tiende a provocar, como consecuencia ineludible, el aumento de la apatía de los ciudadanos. En consecuencia, difícilmente puede alejarse la falta de interés de los ciudadanos como causa justificativa de su no participación" (1994: 99).

Otro tema importante respecto a la participación y en especial a la de jóvenes es que, como dice Barber (2000), lastimosamente depende del ocio; del tiempo necesario para participar en los debates, en mecanismos de democracia directa, en foros, en discusiones, en militancia. La democracia 
se construye y se mantiene mediante la participación individual, pero la sociedad está estructurada para desalentarla. El único periodo destinado a la participación individual es el fijo para votar, que quizá promedia una hora por año. De esta forma, la participación se vuelve prescindible y se la reduce a una actividad menor que requiere sacrificar tiempo formalmente asignado a otras cosas.

Cambiar esto probablemente depende mucho de los partidos. Por ello, Barber (2000) señala que las estrategias que hay que seguir no son económicas ni técnicas sino políticas y culturales. Hacer que las aficiones, el voluntariado cívico, el arte y la cultura, sean tan provechosos como el trabajo; que la educación cívica de calidad sea accesible y atractiva para todos.

A esto se suma una realidad sudamericana y claramente ecuatoriana, y es que, aunque la política y su ejercicio es un derecho, en la práctica es un privilegio. Para ser candidato o incluso tan solo ser militante activo, los propios actores declaran que se necesita dinero. Y los jóvenes por lo general no lo tienen. Convirtiendo así a la política en prescindible cuando se trata de recursos económicos.

Las organizaciones políticas ya no le hablan al mismo elector de hace 30 años, por eso están obligados a concebir nuevas formas de hacer política. Los partidos no van a desaparecer, al menos no ahora, y seguirán siendo el camino al poder y a la toma de decisiones. Pero las estructuras deben adaptarse a la transformación de la participación, que generalmente viene desde los jóvenes, y desalentar la desafección política. Para profundizar en esta animosidad, y aterrizarla al caso ecuatoriano, es fundamental entender el auge y caída de los partidos como un detonante de este escenario.

\section{Claves del escenario político ecuatoriano para entender la relación entre jóvenes y partidos}

Los partidos políticos como actores clave en procesos electorales y, principalmente, como canales de interacción política entre la sociedad civil (en el más amplio sentido de John Locke) y el Estado, vienen enfrentando 
una serie de obstáculos para adaptarse a las democracias modernas. Lo que es grave considerando que, por definición, son el núcleo de la democracia representativa.

Aparentemente, los partidos ecuatorianos se han centrado en definirse en términos de Sartori "cualquier grupo político que se presenta en elecciones, y es capaz de colocar a través de elecciones, candidatos para cargos públicos" (Sartori 1980). Es decir, en ser maquinarias electorales que se activan únicamente para atraer votos y se desmovilizan en periodo no electoral. Pero no solo eso, además, asumieron una actitud de partidos catch all. Otto Kirchheimer los define como partidos atrapa todo, que renuncian a los intentos de incorporar moral y espiritualmente a las masas y dirigen su atención en captar el mayor número de electores; sacrificando, por tanto, una penetración ideológica más profunda por un alcance más amplio y un éxito electoral inmediato (Puhle 2007).

Lo peor de esto es que ese comportamiento desincentiva la participación. Participación entendida como ser parte del partido, de actividades permanentes, de capacitaciones, de formación partidaria, de trabajo en territorio. Los partidos adoptan esta actitud catch all para elecciones, pero su estructura más formal (directivos y dueños del partido) es cerrada, inflexible, sumamente ideológica. Entonces, para adentro son rígidos, pero hacia afuera (durante elecciones) son extremadamente incluyentes, a tal punto que llega a ser difícil distinguir un partido de otro.

Por supuesto, esto es resultado de un proceso histórico en el que el sistema electoral ha jugado un rol fundamental. A través de reglas electorales los partidos se han fortalecido o debilitado en cuanto a su capacidad de representar intereses ciudadanos. Lo paradójico es que las reglas electorales son definidas por los propios partidos representados en la Asamblea Nacional, siendo jueces y parte. Además, cada diseño electoral ha respondido al arreglo político del momento. En Ecuador los sistemas electorales han cambiado acorde al contexto político.

Estas variaciones son ilustradas por Freidenberg y Pachano (2015) en siete ciclos: 


\section{a. Primer ciclo}

Tras el retorno a la democracia en Ecuador (1979), la primera reforma es en 1983. Una de las modificaciones más importantes fue la redefinición de la estructura del Congreso, ahora Asamblea Nacional, diferenciando a los diputados nacionales (carácter político) de los provinciales (carácter territorial), en una especie de descentralización del poder. Y se derogó el umbral de registro para los partidos políticos.

\section{b. Segundo ciclo}

En 1985 cambia el método de asignación de escaños para el Congreso. Pasa de un sistema proporcional a uno de tipo mayoritario que liquidó la representación de las minorías. Lo más importante de este ciclo es que, juntamente con esta elección, hubo un plebiscito que eliminó la posibilidad de participación directa de independientes como candidatos. Lo que sin duda fortalece a los partidos como único mecanismo para acceder a un cargo de elección popular.

\section{c.Tercer ciclo}

En 1993 se introduce nuevamente un umbral mínimo de votación para mantener el registro de los partidos (4\%). Esto se mantuvo hasta 1994 y se reinstituyó en 1996, limitando la participación de partidos pequeños y fortaleciendo a los grandes y tradicionales.

\section{d. Cuarto ciclo}

Para 1994, a través de un plebiscito, se permitió la reelección inmediata de los diputados para otro periodo de funciones. Hasta ese momento solo se podían postular luego de transcurrido un periodo, aunque se permitía la reelección cruzada. Es decir, que los nacionales postulen como provinciales y viceversa. El resultado fue un reciclaje permanente de políticos, debilitando la importancia de formar cuadros para el recambio.

\section{e. Quinto ciclo}

En 1996, como parte de un paquete de reformas constitucionales, 
se eliminó la prohibición de formar alianzas, permitiendo que los movimientos de carácter local puedan participar abanderados por un movimiento de carácter nacional. Esto permitió que los nacionales se despreocuparan por fortalecerse en territorio y aprovecharan el despliegue de estos movimientos para tener penetración local. Así, cada vez se hacía menos necesario formar cuadros o bases con visión nacional, alejándose del contacto ciudadano.

\section{f. Sexto ciclo}

En 1997 a través de un plebiscito se cambió a un tipo de votación personalizada, que iba acorde al método de asignación de escaños de doble cociente; $y$, se adoptó listas abiertas distorsionando el valor del voto. Estas modificaciones debilitan al partido y fortalecen a los candidatos de manera individual. Tanto la lista abierta como el voto personalizado hacen que las estructuras partidarias no tengan peso frente a la decisión del elector. Incluso puede generar un voto sin correspondencia ideológica. Por ejemplo, un mismo elector votando por un candidato de izquierda y otro de derecha.

\section{g. Séptimo ciclo}

En 1998 se introdujo el método D'Hondt, haciendo que los partidos se interesen nuevamente en fortalecerse como organización para buscar un voto en plancha, a pesar del voto personalizado y listas abiertas. Pero también generó pugnas entre los candidatos de una misma lista. Y para el 2005 se introduce la fórmula de ponderador exacto.

Actualmente, el sistema electoral ecuatoriano mantiene el voto personalizado múltiple, las listas abiertas, el método D'Hondt para asambleístas nacionales y Hare para provinciales, y los movimientos locales pueden hacer alianzas con los nacionales. El surgimiento de movimientos locales es importante para entender el auge y caída de los partidos en Ecuador. De repente el sistema de partidos pasó, en cuestión de años, "desde una iniciativa que buscaba el fortalecimiento de unidades partidistas nacionales hasta, en los últimos años, 
una tendencia que buscaba quitar a los grandes partidos el monopolio de la representación política" (Pachano 2016: 152).

El problema con esto es que es probable que al "perder" el monopolio de la representación política, los partidos nacionales, grandes y tradicionales, optaran por debilitar sus estructuras partidarias en territorio, aprovechando la penetración territorial de los movimientos locales. Con ello se vuelve innecesario fortalecer bases a nivel nacional, formar cuadros, capacitar gente, trabajar en territorio.

Si los partidos políticos en Ecuador son solo maquinarias electorales que se activan únicamente en elecciones, el surgimiento de gobiernos locales les facilitó el trabajo. Su aparente debilitamiento o pérdida de monopolio del poder, les permitió fortalecerse para elecciones, con menos recursos y con menor esfuerzo.

Ante ese escenario la desafección de la sociedad por la política y, en especial, de los jóvenes parece ser una consecuencia de estas dinámicas del sistema político ecuatoriano. Lo que sumado a la inestabilidad política del país (10 presidentes en 10 años) justo en el periodo en el que nacieron y crecieron los actuales jóvenes ecuatorianos (1996-2006), explicaría por qué ellos tienen cierta percepción negativa sobre la política.

Además, luego de este periodo de inestabilidad, vinieron 10 años de estabilidad con un solo presidente (Rafael Correa) que llegó al poder siendo un outsider. Lo hizo con un movimiento nuevo (Alianza PAIS) que discursivamente era antisistema porque renegaba de la tradicional partidocracia. Movimiento que, en su momento, logró captar el interés de muchos jóvenes que le apostaban a "otra forma" de hacer política. Lastimosamente, cuando Alianza PAIS entra en crisis con la salida de Correa del país y su ruptura con el actual presidente de la República, Lenín Moreno, se afecta fuertemente el interés de esos jóvenes por la política y peor aún con los casos de corrupción que han salido a la luz.

Adicionalmente, para entender el nivel de desafección, de participación y representación de los jóvenes, es importante observar las cifras. 


\section{Participación política de los jóvenes ecuatorianos en cifras}

Cabe recalcar que para objeto de esta investigación se ha considerado jóvenes a aquellos ubicados entre 16 y 35 años. Esto, porque desde los 16 años es permitido votar y 35 es la edad necesaria para ser presidente de la República del Ecuador.

En la siguiente Tabla 2 se puede observar un comparativo de candidatos jóvenes en las elecciones seccionales 2009, 2014 y 2019.

Tabla 2.

Comparativo candidatos entre 18 y 35 años, elecciones seccionales 2019, 2014, 2019

\begin{tabular}{|l|c|c|c|}
\hline \multicolumn{1}{|c|}{ Candidatura } & $\begin{array}{c}\text { Candidatos } \\
\mathbf{2 0 0 9}\end{array}$ & $\begin{array}{c}\text { Candidatos } \\
\mathbf{2 0 1 4}\end{array}$ & $\begin{array}{c}\text { Candidatos } \\
\mathbf{2 0 1 9}\end{array}$ \\
\hline Prefectos & 10 & 10 & 11 \\
\hline Concejales rurales & 1162 & 839 & 1105 \\
\hline Alcaldes municipales & 112 & 116 & 147 \\
\hline Concejales urbanos & 2508 & 1862 & 2421 \\
\hline Vocales de juntas parroquiales & 7717 & 7536 & 10111 \\
\hline TOTAL & 11509 & 10363 & 13795 \\
\hline
\end{tabular}

Fuente: CNE.

Elaboración: Gabriel Velastegui, Instituto de la Democracia.

Como se puede observar la participación política de jóvenes no ha tenido un comportamiento creciente, dado que en 2014 baja y luego en 2019 vuelve a subir de manera importante. Si comparamos esto con los jóvenes electos se observa lo siguiente en la Tabla 3.

Tabla 3.

Comparativo electos entre 18 y 35 años, elecciones seccionales 2019, 2014, 2019 


\begin{tabular}{|l|c|c|c|}
\hline \multicolumn{1}{|c|}{ Dignidad } & Electos 2009 & Electos 2014 & Electos 2019 \\
\hline Prefectos & 1 & 1 & 0 \\
\hline Concejales rurales & 137 & 119 & 95 \\
\hline Alcaldes municipales & 21 & 24 & 18 \\
\hline Concejales urbanos & 270 & 266 & 172 \\
\hline Vocales de juntas parroquiales & 1149 & 1293 & 1207 \\
\hline TOTAL & 1578 & 1703 & 1492 \\
\hline
\end{tabular}

Fuente: CNE.

Elaboración: Gabriel Velastegui, Instituto de la Democracia.

Los resultados son inversamente proporcionales. Mientras en 2014 hubo menos candidatos jóvenes, ese mismo año hubo más jóvenes electos. Lo que podría motivar una investigación posterior a fin de determinar cuáles son las razones por las que el elector decide elegir o no a un joven.

Si analizamos las últimas elecciones seccionales (2019) a profundidad, podemos decir que constaban en el padrón electoral 13'261.994 electores. De ese total, el 22\% (2'928.636) es facultativo (entre de 16 y 17 años, mayores de 65 años, ecuatorianos en el exterior, integrantes de las Fuerzas Armadas y Policía Nacional, personas con discapacidad, analfabetas y migrantes viviendo en el Ecuador al menos 5 años). Y de ese 22\% facultativo el casi $23 \%$ (664.502) son adolescentes entre 16 y 17 años.

El 78\% restante (10'333.358) corresponde a voto obligatorio (mayores de 18 años hasta 65 años y privados de la libertad sin sentencia condenatoria ejecutoriada). De ese 78\%, el 50\% (5'158.771) tiene entre 18 y 35 años. Lo que significa que del $100 \%$ de electores, el $44 \%$ son jóvenes y adolescentes. Ese porcentaje de votos es más que suficiente, incluso, para poner presidente de la República. Si los partidos ignoran el voto joven, están perdiendo la mejor oportunidad para ganar cualquier escaño.

Es importante también observar la Tabla 4 que presenta el número de candidaturas jóvenes y electos de las últimas elecciones 2019, por dignidad: 


\section{Tabla 4.}

Número y porcentaje de candidatos entre 18 y 35 años por dignidad: Ecuador 2019

\begin{tabular}{|l|c|c|c|}
\hline \multicolumn{1}{|c|}{ Dignidad } & $\begin{array}{c}\text { N. de candidatos } \\
\text { entre 18 y 35 años }\end{array}$ & $\begin{array}{c}\text { Total candidatos } \\
\text { participantes }\end{array}$ & $\begin{array}{c}\text { Porcentaje } \\
\text { del 100\% }\end{array}$ \\
\hline Alcaldes & 147 & 1.875 & $8 \%$ \\
\hline Concejales rurales & 1.105 & 3.688 & $30 \%$ \\
\hline Concejales urbanos & 2.421 & 8.791 & $28 \%$ \\
\hline Prefecto y vice prefecto & 11 & 223 & $5 \%$ \\
\hline Vocales de juntas parroquiales & 10.111 & 26.935 & $38 \%$ \\
\hline Total de candidatos a nivel nacional & 13.795 & 41.512 & $34 \%$ \\
\hline
\end{tabular}

Fuente: Dirección Nacional de Estadística del Consejo Nacional Electoral de Ecuador, 2019.

Elaboración: Propia.

Aquí se evidencia que la participación juvenil como candidatos para elecciones pluripersonales es mayor (no llega ni al 40\%) a su participación en elecciones unipersonales o en binomio (no llega ni a 10\%). Así, del total de candidatos a nivel nacional, solo el $34 \%$ fueron jóvenes. Además, sus candidaturas son mayores en la zona rural.

Si hacemos el mismo ejercicio con candidatos electos, los resultados empeoran.

\section{Tabla 5.}

Número y porcentaje de candidatos entre 18 y 35 años electos por dignidad: Ecuador 2019

\begin{tabular}{|l|l|l|l|}
\hline \multicolumn{1}{|c|}{ Dignidad } & $\begin{array}{l}\text { N. de electos entre } \\
\mathbf{1 8 ~ y ~ 3 5} \text { años }\end{array}$ & Total electos & $\begin{array}{c}\text { Porcentaje } \\
\text { del 100\% }\end{array}$ \\
\hline Alcaldes & 18 & 221 & $8 \%$ \\
\hline Concejales rurales & 95 & 443 & $21 \%$ \\
\hline Concejales urbanos & 172 & 864 & $20 \%$ \\
\hline Prefecto y vice prefecto & 0 & 23 & $0 \%$ \\
\hline Vocales de juntas parroquiales & 1.207 & 4.094 & $29 \%$ \\
\hline Total de candidatos a nivel nacional & 1.492 & 5.645 & $27 \%$ \\
\hline
\end{tabular}

Fuente: Dirección Nacional de Estadística del Consejo Nacional Electoral de Ecuador, 2019. Elaboración: Propia. 
Se evidencia que el porcentaje de jóvenes electos para elecciones pluripersonales es mayor (no llega ni al 30\%) a su participación en elecciones unipersonales o en binomio (no llega ni al 10\%). Y que los jóvenes tienen mayores posibilidades de ganar en zonas rurales.

En resumen, del total nacional de candidatos electos solo el $27 \%$ fueron jóvenes (18 a 35 años), una cifra muy baja considerando que el 50\% de electores tienen entre 16 y 35 años. Por lo que claramente los resultados no reflejan, a manera de espejo, la diversidad de la composición del electorado.

Por lo tanto, las cifras muestran la importancia de los jóvenes como electores y su poca participación como candidatos y autoridades electas. Es decir, que los pocos jóvenes que deciden participar de la política tienen pocas probabilidades de ganar, lo cual, sin duda, puede desincentivarlos.

\section{Resultados del estudio ¿Qué son los jóvenes para los partidos? ¿Qué son los partidos para los jóvenes?}

Para objeto de este estudio se realizaron reuniones con dos grupos. Por un lado, directivos de partidos nacionales, con sus candidatos jóvenes para las últimas elecciones y sus militantes jóvenes. Y por otro, con jóvenes de colectivos de la sociedad civil. Cabe mencionar que, en el caso de partidos, para las reuniones se separaron a directivos de candidatos y militantes, para evitar cualquier tipo de presión o incidencia en las respuestas. Los resultados se presentan a continuación.

\section{Organizaciones políticas}

De los 22 partidos y movimientos políticos nacionales inscritos en Ecuador, solo se logró la reunión con seis (Izquierda Democrática, CREO, Sociedad Patriótica, Partido Socialista, Pachakutik, y Alianza PAIS)². Los demás,

2 En Izquierda Democrática la reunión fue con 17 jóvenes entre 18 y 35 años, de los cuales 8 eran mujeres. En CREO la reunión fue con 48 jóvenes de entre 18 y 35 años, de los cuales 23 eran mujeres. Del Partido Socialista fueron 7 jóvenes entre 18 y 35 años, de los cuáles 3 eran mujeres. En Alianza PAIS nos reunimos con 5 jóvenes, 2 mujeres y 3 hombres entre 18 y 35 años. En Pachakutik, la reunión fue con 3 jóvenes hombres entre 18 y 35 años, y en Sociedad Patriótica con dos jóvenes, un hombre y una mujer, de 21 y 25 años. La diferencia entre número de entrevistados dependió de la propia organización política dado que la convocatoria a sus juventudes la hicieron ellos mismo. Por lo tanto, fueron los propios partidos los que definieron con quién sería la reunión. 
lastimosamente, o nunca contestaron, o nunca concretaron fecha para reunión o respondieron que estando en tiempos no electorales les era imposible reunir a sus militantes y menos aún a sus candidatos, que al perder se habían desvinculado del partido.

\section{Con los entrevistados se trabajaron las siguientes preguntas:}

\begin{tabular}{|c|c|c|}
\hline Directivos & Candidatos & Militantes \\
\hline $\begin{array}{l}\text { ¿Cuentan con una estructura } \\
\text { de jóvenes? }\end{array}$ & $\begin{array}{l}\text { ¿Por qué decidieron ser candi- } \\
\text { datos? }\end{array}$ & $\begin{array}{l}\text { ¿Por qué decidieron } \\
\text { unirse? }\end{array}$ \\
\hline $\begin{array}{l}\text { ¿Por qué estos jóvenes han } \\
\text { decido participar del partido? }\end{array}$ & $\begin{array}{l}\text { ¿Desde cuándo pertenecían al } \\
\text { partido por el que participaron? }\end{array}$ & $\begin{array}{l}\text { ¿Les costó tomar la } \\
\text { decisión? }\end{array}$ \\
\hline $\begin{array}{l}\text { ¿Por qué cree que otros jóve- } \\
\text { nes no lo hacen? }\end{array}$ & $\begin{array}{l}\text { ¿El partido los preparó o capaci- } \\
\text { tó? ¿En qué? ¿Desde cuándo? }\end{array}$ & $\begin{array}{l}\text { ¿Desde cuándo les intere- } \\
\text { sa la política? }\end{array}$ \\
\hline $\begin{array}{l}\text { ¿Tienen una agenda de activi- } \\
\text { dades con ellos? }\end{array}$ & $\begin{array}{l}\text { ¿Han participado en otras oca- } \\
\text { siones como candidatos? }\end{array}$ & $\begin{array}{l}\text { ¿Qué actividades realizan } \\
\text { al interior del partido? }\end{array}$ \\
\hline $\begin{array}{l}\text { ¿En qué temas los capacitan } \\
\text { o forman? }\end{array}$ & ¿Han pertenecido a otro partido? & $\begin{array}{l}\text { ¿Qué creen que pueden } \\
\text { lograr siendo parte de un } \\
\text { partido? }\end{array}$ \\
\hline $\begin{array}{l}\text { ¿De qué manera participan } \\
\text { dentro del partido? }\end{array}$ & $\begin{array}{l}\text { ¿Qué creen que les permitió } \\
\text { ganar o que les faltó para ganar? }\end{array}$ & $\begin{array}{l}\text { ¿Creen que siendo parte } \\
\text { del partido un día pueden } \\
\text { llegar a ser candidatos? }\end{array}$ \\
\hline $\begin{array}{l}\text { ¿Tienen alguna estrategia } \\
\text { para atraer a los jóvenes? }\end{array}$ & $\begin{array}{l}\text { ¿Cómo manejaron su condición } \\
\text { de jóvenes dentro de la campaña } \\
\text { electoral y en sus propuestas? }\end{array}$ & $\begin{array}{l}\text { ¿Si llegan a un cargo } \\
\text { público qué les gustaría } \\
\text { cambiar? }\end{array}$ \\
\hline $\begin{array}{l}\text { ¿De qué manera creen que los } \\
\text { jóvenes aportan a su partido? }\end{array}$ & $\begin{array}{l}\text { ¿Qué los diferencia de otros } \\
\text { candidatos? }\end{array}$ & $\begin{array}{l}\text { ¿Qué piensan sus amigos } \\
\text { y familiares de que sean } \\
\text { parte de un partido? }\end{array}$ \\
\hline $\begin{array}{l}\text { ¿Qué posibil } \\
\text { jóvenes de se }\end{array}$ & $\begin{array}{l}\text { ie los jóvenes votaron } \\
\text { es? }\end{array}$ & $\begin{array}{l}\text { ¿Por qué a sus amigos no } \\
\text { les interesa ser parte? }\end{array}$ \\
\hline $\begin{array}{l}\text { ¿Cuántos de sus militantes } \\
\text { jóvenes o que empezaron en } \\
\text { el partido siendo jóvenes se } \\
\text { han convertido en candidatos } \\
\text { y cuántos han ganado? }\end{array}$ & $\begin{array}{l}\text { ¿Han sentido segregación o } \\
\text { discriminación como jóvenes en } \\
\text { la política? }\end{array}$ & $\begin{array}{l}\text { ¿Por qué creen que mu- } \\
\text { chos jóvenes no son parte } \\
\text { de un partido? }\end{array}$ \\
\hline $\begin{array}{l}\text { ¿Han hecho un perfil de su } \\
\text { elector joven? }\end{array}$ & $\begin{array}{l}\text { ¿Volverían a ser candidatos? } \\
\text { ¿Por el mismo partido? }\end{array}$ & $\begin{array}{l}\text { ¿Qué creen que podrían } \\
\text { hacer los partidos para } \\
\text { atraer más jóvenes? }\end{array}$ \\
\hline $\begin{array}{l}\text { ¿Qué creen que los jóvenes } \\
\text { buscan, piden o esperan de } \\
\text { los partidos? }\end{array}$ & $\begin{array}{l}\text { ¿Además de ser candidatos } \\
\text { antes cumplían con otras activi- } \\
\text { dades al interior del partido? }\end{array}$ & $\begin{array}{l}\text { ¿Qué creen que los } \\
\text { jóvenes esperan de los } \\
\text { partidos? }\end{array}$ \\
\hline
\end{tabular}

Elaboración: propia. 
Empezaremos con los resultados de los militantes jóvenes porque sus respuestas permiten entender el comportamiento de los candidatos y los directivos. Al respecto, uno de los hallazgos más interesantes fue que un gran número de los jóvenes entrevistados que participan de los partidos antes mencionados vienen de familias vinculadas o interesadas en la política. Fueron candidatos, autoridades, militantes o activistas, y, por lo tanto, durante su crianza participaron de varias conversaciones o reflexiones políticas en casa.

Otro hallazgo es que, para la mayoría de estos chicos, su interés por la política se activa desde el colegio o universidad, participando de gobiernos estudiantiles. Es decir, son jóvenes que siempre estuvieron interesados en estos temas, por lo que su participación como candidato o militante en un partido era probable.

No se encontró una similitud en formación profesional. Los jóvenes no necesariamente estudian derecho, ciencia política o relaciones internacionales, vienen de otras ramas como veterinaria, ingeniería mecánica, física pura, contabilidad, comunicación, diseño, artes; rompiendo el mito de que el joven interesado en la política estudia política. Y esto sucede porque para ellos, la política no solo es la gestión de lo público.

Para estos jóvenes, es servicio a los demás, es labor social, es ayudar al otro, es generar espacios de participación, es encontrarse en el arte, es escuchar al otro, es hacer que otro los escuche. Por eso no sintieron la necesidad de estudiar una carrera aparentemente a fin, porque consideran que desde sus espacios también contribuyen a la sociedad. Estos jóvenes no ven la política como ser candidatos, participar de elecciones, ganar y hacer gestión pública.

Hay un pequeño grupo de jóvenes entre los entrevistados que si quiere participar en elecciones con una candidatura, pero la mayoría no piensa en eso. En ellos existe la conciencia de que para ser autoridad electa se necesita preparación y muchos no creen estar aún preparados para ello, pero se están formando para un día lograrlo, al contrario de muchos adultos que aceptan cargos políticos sabiendo que no tienen ni la preparación, ni las capacidades, ni las competencias necesarias. 
Los jóvenes que participaron del estudio, asimismo, dicen que necesitan estructuras/partidos menos totalizantes, más flexibles, más participativas. Dispuestas a aceptar dobles o triples militancias, que dejen de considerar la afiliación como inserción en una comunidad filo religiosa, que acepten la crítica interna, asuman los abandonos, etcétera.

Respecto a la opinión de sus amigos y familiares acerca de su participación en la política o en los partidos, es dividida dependiendo del partido. A algunos los desalientan con frases como "te vas a volver corrupto", "vas a cambiar", "vas a robar", "te harás como los políticos mentirosos". Pero hay otros que reciben apoyo, cuyas familias están felices de que estén activos en cosas saludables y productivas, incluso han logrado invitar amigos a participar. Esto aparentemente depende de la percepción ciudadana que exista de cada partido.

De hecho, los jóvenes que reciben rechazo creen que la mayoría de los chicos no participan de la política porque no confían en ella, porque creen que es corrupta y que solo los que tienen dinero o poder, pueden llegar lejos. Otros argumentan que es porque la política les parece aburrida, difícil, compleja, densa y rodeada de intereses. Para muchos jóvenes la política es un privilegio y no un derecho, porque para participar, por ejemplo, como candidatos se necesita dinero o incluso tan solo para movilizarse a recibir capacitaciones o participar de eventos.

Para ellos, los partidos deberían ser instituciones que escuchan, que aceptan la opinión de todos, que son flexibles, que apoyan sus ideas y proyectos, que los impulsan, que los hacen parte de las decisiones. Espacios para compartir. Un lugar donde puedan ser ellos, se distraigan de sus actividades formales, desde dónde puedan trabajar con la gente.

Ninguno de los chicos recibe capacitación partidaria o ideológica. Cuando entran al partido reciben una introducción, pero después nunca más. En algunos partidos esto sucede de manera voluntaria y planificada. No realizan capacitaciones formales porque saben que eso aleja a los jóvenes, ellos no quieren recibir más clases, quieren hacer cosas prácticas no teóricas. Por lo que prefieren acercarse a ellos a través de otro tipo de actividades más lúdicas o de trabajo social. 
Estos chicos exigen de los partidos flexibilidad ideológica. Que puedan expresar sus comentarios, ideas, proyectos sin ser censurados. Que no limiten sus opiniones a solo pensar como el partido quiere que piensen. No quieren ser adoctrinados.

Los jóvenes se sienten subestimados. Consideran que los adultos del partido no tienen apertura para aceptar y escuchar sus propuestas, y lo definen como "cacicazgos". Para ellos los "viejos" tienen miedo de ser reemplazados y por eso no les dan espacios. Perciben un monopolio de poder, de la palabra y de la toma de decisiones.

Cabe decir que esto no sucedió en todos los partidos. Hubo jóvenes que dijeron ser escuchados e incluso ser apoyados económicamente por los directivos para poner en marcha sus proyectos. Que tal es su incidencia en las decisiones, que los dirigentes jóvenes tienen relaciones horizontales, incluso, con las autoridades electas del partido.

Los jóvenes también exigen que los partidos revisen sus agendas, porque no se ven representados. Piden que los partidos se acerquen a las bases y que no esperen que sea la gente quien los busque. Que no se activen solo en elecciones.

Finalmente, cabe recalcar que se identificaron tres tipos de jóvenes. Primero, los que sienten que los partidos los utilizan y, por lo tanto, ellos también utilizan al partido para sus propios intereses. Segundo, están aquellos que encontraron en el partido su lugar, un espacio para compartir con gente que comparte su interés por realizar trabajo social. Y tercero, el joven que cree en la política, que cree en su partido, que está convencido de la ideología y es bastante respetuoso a las reglas del partido, por convencimiento, no por obligación (este joven es parte de un partido con una ética comunitaria muy fuerte).

Cuando hablamos con candidatos nos enfrentamos a otra realidad. Por un lado, tienes el joven que para poder ser candidato tuvo que sacrificar hasta el dinero destinado a sus estudios, incluso, el presupuesto de sus propios amigos y familia. Que estuvo tercero, cuarto y hasta quinto en la lista. Que no recibió apoyo económico para la campaña de parte del partido. 
Existen candidatos jóvenes que fueron ofendidos, callados, limitados en cuanto a su promoción individual. Incluso les impidieron subir fotos a sus redes sociales argumentando que al hacer campaña individual perjudicaban al primero de la lista. Claramente, no los habían candidateado para ganar. Aun así, muchos logran escalar puestos en la lista. Es decir, estando terceros lograron el segundo puesto. Ellos adjudican esto a que la gente, tanto joven como adulta, votó por ellos por su frescura, porque son nuevos, porque creen que aún no están "manchados" por la corrupción, porque los ven sinceros. Cuentan que durante su trabajo en territorio mucha gente les dijo "voy a votar por usted, pero no por su partido, porque en su partido no creo, pero en usted s'́".

Por eso, cuando se les hablaba de una posible reforma al sistema electoral ecuatoriano para pasar a listas cerradas, ellos argumentaban que les haríamos mucho daño. Porque para los jóvenes el partido solo es el camino para estar en lista y participar de elecciones (de manera independiente no podrían hacerlo), pero que su poder está en el voto individual. Como los partidos los ponen en los últimos puestos, si las listas fueran cerradas, sería imposible para ellos ganar un escaño.

Pero también encontramos otro tipo de candidato joven agradecido con la organización política por haberlo puesto en la lista, aunque haya sido en último puesto. Porque creen que fue un aprendizaje. Que en la política todo es un proceso. Que ser candidato, aun sabiendo que no podía ganar, le ayudó para conocer a la gente, para conocer las necesidades de sus territorios. Ellos decían "hablar con la gente en campaña es difícil, a veces son groseros, no te escuchan, te ignoran, y ser candidato me ayudó para ir preparándome para el futuro, para cuando esté listo para desempeñar un cargo".

Respecto a las reuniones con los directivos, también se observaron tres tipos. Unos bastante inflexibles respecto a cómo deben hacerse las cosas en el partido, reticentes a escuchar las propuestas de los jóvenes, convencidos de que por darles un espacio en la sede ya están incluidos. Otros que han dado apertura a los jóvenes entendiendo sus propias dinámicas, pero limitando su nivel de incidencia. Son directivos en los que se percibe cierta molestia por tener que ceder a la participación de jóvenes, pero que lo hacen porque 
entienden que es necesario para atraerlos. Y finalmente, otro tipo de directivo que ve en los jóvenes una oportunidad para fortalecer a la organización política. Que busca estrategias para atraer jóvenes líderes de comunidades que quieren apoyo para hacer labor social o emprender. Que tienen gran capacidad de convocatoria. Un tipo de directivo que se acerca a los jóvenes y se relaciona con ellos de forma horizontal.

Todas estas diferencias no son casualidades sino causalidades. Tienen que ver con la forma en la que está concebido el partido, con sus directivos, con su visión respecto al aporte de los jóvenes a la organización. Con su preparación hacia el futuro.

\section{Jóvenes que pertenecen a colectivos}

Con estos jóvenes, el objetivo principal era entender por qué si les interesa la política no son parte de un partido. No se menciona el nombre de los colectivos entrevistados pues fue su pedido no ser visibilizados. Con ellos se trabajó el siguiente banco de preguntas:

\section{Tabla 7.}

Preguntas con jóvenes entre 16 y 35 años de colectivos

\begin{tabular}{|l|l|}
\hline \multicolumn{2}{|c|}{ Jóvenes de colectivos o sociedad civil organizada } \\
\hline ¿Hace cuánto son parte de la organización? & ¿Por qué decidieron unirse? \\
\hline $\begin{array}{l}\text { ¿Desde cuándo les interesa la política, la labor } \\
\text { social, el activismo? }\end{array}$ & $\begin{array}{l}\text { ¿Qué actividades realizan al interior de } \\
\text { la organización? }\end{array}$ \\
\hline $\begin{array}{l}\text { ¿Qué creen que pueden lograr siendo parte de la } \\
\text { organización? }\end{array}$ & $\begin{array}{l}\text { ¿Creen que siendo parte de la organiza- } \\
\text { ción un día pueden llegar a ser candida- } \\
\text { tos o autoridades? }\end{array}$ \\
\hline $\begin{array}{l}\text { ¿Qué piensan sus amigos y familiares de que } \\
\text { sean parte de una organización como esta? }\end{array}$ & $\begin{array}{l}\text { ¿Por qué creen que muchos jóvenes no } \\
\text { son parte de un partido? }\end{array}$ \\
\hline $\begin{array}{l}\text { ¿Qué creen que podrían hacer los partidos para } \\
\text { atraer más jóvenes? }\end{array}$ & $\begin{array}{l}\text { ¿Qué creen que los jóvenes esperan de } \\
\text { los partidos? }\end{array}$ \\
\hline
\end{tabular}

Elaboración: propia. 
El hallazgo fue que para ellos los partidos son estructuras ajenas a la realidad del pueblo, mientras que los colectivos trabajan directamente con las personas en las calles, los escuchan, identifican sus necesidades y sus problemas. Su motivación es el trabajo social, el ayudar a la gente. Son jóvenes que no necesariamente estuvieron involucrados a la política desde el colegio o la universidad, pero sí a grupos de jóvenes artísticos, culturales, sociales. Son ajenos a los conceptos teóricos de la política, pero para ellos el servicio al otro es lo que debería ser la política.

Su interés no es electoral. De hecho, desconocen qué ofrecen los partidos porque solo los ven en elecciones. Para ellos, los partidos no son canales de participación entre los jóvenes y lo público, y por ello buscan otras opciones y mecanismos. Para estos jóvenes, los partidos se han convertido en maquinarias electorales que responden a coyunturas políticas, mientras lo que ellos buscan son comunidades permanentes.

Muchos partidos los contactan para ser candidatos, porque saben que convocan a muchos jóvenes. Pero han rechazado las propuestas por dos razones. Primero porque no creen estar preparados para asumir un cargo de elección popular y segundo, y más importante, porque se sienten utilizados. Saben que si los ponen en lista sería solo por interés de obtener votos y eso a ellos los ofende y no les interesa.

Sus colectivos les ofrecen algo que ellos no encuentran en los partidos: flexibilidad ideológica, porque lo que buscan es gente que comparta el mismo fin que es ayudar a los demás. Además, el ingreso es fácil y no hay rechazo. Son chicos que se sienten diferentes y que buscan un lugar dónde encontrarse y poder ser ellos mismo. Estos argumentos coinciden con los del movimiento juvenil Álvaro Ulcué Chocué del Norte del Cauca en Colombia cuyo estudio arroja que

En cuanto a los intereses de relacionamiento e identificación se destacan, la búsqueda e identificación con un grupo de pares, el interés de entrar en espacios de socialización diferentes a la familia, la necesidad de visibilización y reivindicación social como sujetos jóvenes, el interés en espacios de recreación para hacer cosas distintas a las cotidianas que 
imponen sus roles y las ganas de expandir el horizonte de posibilidad de sus mundos, más allá de la fronteras de sus casas y parcelas. Estos jóvenes se vinculan y permanecen en el movimiento porque encuentran en él, un espacio de encuentro e intercambio entre pares en el cual pueden expresar y sentir a través del cuerpo, la palabra y la memoria (A, et al. 2011:25).

Estos chicos de colectivos sienten que la ética, la transparencia y la confianza son más fuertes al interior de su colectivo e inexistentes en un partido. Además, sus decisiones son democráticas, se toman entre todo el colectivo, todos tienen voz, no hay jefes superiores.

Finalmente, hay que reconocer que mientras los partidos adjudican la falta de capacitación a su militancia por falta de presupuesto, estos chicos, en su mayoría de recursos limitados, realizan capacitaciones, encuentros, incluso tienen vacacionales impartidos por los mismos miembros. Buscan la forma de aprovechar las capacidades de todos. No ponen excusas.

Considerando estos hallazgos tanto de militantes, como de candidatos, directivos y miembros de colectivos, en el siguiente capítulo podemos encontrar una breve propuesta de estrategias a manera de conclusión para que los partidos intenten recomponer su relación con los jóvenes.

\section{Estrategias para recomponer la relación entre jóvenes y partidos (reflexiones finales)}

Todas las estrategias que se proponen a continuación se desprenden del estudio realizado.

Primero, hay que reconvertir a los militantes y simpatizantes en activistas. Los militantes no son un número, no son sólo votos, son personas. Personas con intereses, con necesidades, con motivaciones. Un partido que piensa en los militantes como un número está condenado al fracaso.Si se busca que los jóvenes se interesen por la política, entonces hay que hacer más política. Esto implica realizar actividades sociales, culturales, participativas, permanentes. Que los jóvenes, a través del partido, puedan acercarse al 
territorio, conocer las diversas realidades sociales e incidir en ellas aportando desde sus propias capacidades. El partido debe ser ese ente canalizador de jóvenes líderes que buscan un lugar mejor y brindar todo el apoyo para potenciar sus talentos.

Los partidos no pueden ser rígidos, exclusivos, excluyentes. La mayoría de los jóvenes no entiende de ideologías, pero sí de principios, y su motivación principal es el ayudar a otros. Estos deberían constituirse en organizaciones que impulsen y promuevan la acción, que favorezcan el tránsito entre pensar, decir, hacer, y no en instituciones que esperen de sus militantes personas autómatas a las que les enseñen cómo y qué pensar.

Las sedes de los partidos deberían convertirse en espacios de coworking políticos, abiertos a todos los sectores que quieren cambios, que defienden sus derechos, que desean otra política y que sienten que es posible. $\mathrm{Y}$ aunque se pide flexibilidad, por supuesto que el partido puede poner límites de acuerdo con sus principios ideológicos, pero no límites a las ideas y proyectos de los jóvenes.

Los partidos deben entender que la experiencia es importante para cualquier institución, pero también que nunca se termina de aprender, y los jóvenes tienen una frescura particular, no solo por su edad, sino también por sus conocimientos. Por su capacidad de arriesgarse, de encontrar soluciones, de procesar los cambios.

Esa sinergia entre adultos y jóvenes debe ser aprovechada. Los más antiguos deberían tratar de heredar todo su conocimiento a las nuevas generaciones porque los chicos absorben con gran facilidad las cosas. El día que ellos falten, serán los jóvenes quienes asuman el mando y qué mejor si aprendieron de quienes formaron el partido.

Las relaciones al interior del partido no pueden ser jerárquicas o verticales. Y por supuesto que transformar una organización piramidal en una organización red, no es sencillo. El choque es duro. Pero es inevitable e inaplazable si se quiere reconectar con las formas, los estilos, los modelos y los valores de las nuevas generaciones. 
Este proceso de cambio reconfigurará el poder, que se obtendrá, no por el lugar que se ocupa en el organigrama, sino por el mérito y reputación que se gana y se reconoce en la organización. Organizarse por objetivos y causas, no por votos y menos por cargos.

De hecho, a los jóvenes no les interesa los cargos políticos, ese no es su fin. Creen en los procesos, y si un día se sienten preparados y con la experiencia necesaria para ocupar un cargo tal vez lo piensen. Pero para ellos, ser autoridad es serio y demanda preparación.

Otro punto importante, ligado a la obligatoriedad de los partidos de capacitar a sus militantes, es que no se puede liderar la sociedad sin ideas. Se necesita una organización que se parezca más a un laboratorio que a la clásica concepción de partido de masas complacientes y obedientes. Hay que generar espacios de diálogo y debate, sin ellos no hay política. Los partidos se han quedado sin personas y sin ideas. Y no se sabe qué fue primero. Por eso los colectivos se han vuelto tan atractivos para los jóvenes, porque hay más posibilidad de pensar, de ser creativos, de explorar y emprender.

Otro punto para atender es que la vida partidaria debería ser atractiva, emocionante, una experiencia enriquecedora, que haga que la gente se comprometa. Menos burocratizada.

Y, por último, pero no menos importante, está el desafío de recuperar la credibilidad de los partidos que está más en las actitudes que en las aptitudes. Este es uno de los primeros pasos, imprescindibles, para refundarse y empezar de nuevo. Que la gente, no solo los jóvenes, vuelva a creer en los partidos, no como maquinarias electorales, sino como generadoras del cambio.

Todo lo expuesto nos permite concluir que la relación entre jóvenes y partidos no está totalmente rota, pero sí muy fracturada. Hay posibilidades de recomponerla, pero la mayor parte no depende de los jóvenes sino de los partidos. Eso implica una restructuración profunda de la organización, de sus relaciones de poder, del modelo de organización y, sobre todo, del modelo de participación. Sin esto, la relación -que pende de un hilo- se romperá por completo, convirtiendo a los partidos en simples maquinarias electorales sin incidencia real en el presente y futuro del país (escenario no muy alejado 
del que se vive actualmente). Y, lo más importante, sin jóvenes que quieran asumir el relevo político.

Lo que los partidos ofrecen no es lo que los jóvenes esperan o quieren de las organizaciones o instituciones de las que buscan ser parte. Lo interesante de los hallazgos es que podrían extrapolarse hacia los adultos también. Muchas de las estrategias propuestas pueden ser atractivas para todo aquel que se haya alejado de la política por ser elitista, excluyente, aburrida, compleja, corrupta.

Los jóvenes no son ni egoístas, ni apolíticos. Al contrario, su nivel de indignación con las injusticias sociales, la desigualdad y la pobreza es fuerte. Para muchos de estos jóvenes incluso es su motor. Pero no les interesa ser parte del actual sistema político y sus prácticas.

No forman partidos porque no creen en las instituciones, y porque para muchos el dinero y el tiempo son limitantes. Por eso forman colectivos, grupos de amigos, de personas con intereses comunes. Saben que su nivel de incidencia no será mayor desde esos espacios, pero si logran sacar a un solo chico de las drogas, ya para ellos es un éxito.

Los jóvenes que pertenecen a los partidos no están contentos. Aprovechan cada reunión para intentar ser escuchados y exponer su molestia con las prácticas tradicionales. Pero no se alejan porque saben que los partidos son el medio para acceder a la toma de decisiones y porque muchos de ellos creen en la política (en términos conceptuales) y les gusta, aun sabiendo que sus partidos no son el reflejo de la política que ellos desean hacer.

Al exponer estos resultados a los partidos parte del estudio y a otros como el Partido Social Cristiano, se evidencia incomodidad de parte de los directivos y aceptación por parte de sus militantes. Lo que evidencia la desconexión entre los dueños del partido y la gente. Probablemente, si los partidos escucharan a sus militantes sabrían los resultados de este estudio sin necesidad de que nosotros se los dijéramos. Los partidos no están escuchando, solo están pensando en estrategias para ganar electoralmente, lo que sin duda es el camino hacia su debilitamiento. Un escaño ganado (muchas veces en alianza con organizaciones políticas locales) les garantiza su existencia, pero no su fortaleza. 
Este es un primer acercamiento; aún hay mucho que indagar e investigar para entender las dinámicas de los jóvenes ecuatorianos frente a la política y frente a su relación con las organizaciones políticas. De hecho, en el Estado del Arte fue nula la bibliografía específica encontrada sobre el tema de jóvenes y política en Ecuador. Por lo que todo lo hallado es resultado absoluto del estudio empírico y debe ser analizado como tal.

Todavía hay muchas interrogantes que responder por lo que se recomienda realizar una segunda parte de este estudio con el resto de los partidos nacionales y con las organizaciones locales. Además, se recomienda realizar un evento internacional para intercambiar experiencias con partidos de otros países, no solo de la región, que tengan fuertes estructuras de jóvenes. Esto permitirá ampliar el espectro de la investigación y la caracterización de los jóvenes frente a la política y de los partidos frente a los jóvenes y sus nuevas formas de participación. Al final, lo fundamental es que, tanto este estudio, como cualquiera que se haga posterior sobre el tema será fundamental para fortalecer a las organizaciones políticas ecuatorianas de cara a las elecciones 2021, y general, para fortalecer la democracia. 


\section{Bibliografía}

Agudelo, A., L. Murillo, L. Echeverry, y J. Patiño, (2013). "Participación ciudadana y prácticas políticas de jóvenes en la cotidianidad". En Revista Latinoamericana de Ciencias Sociales, Niñez y Juventud, 11 (2), pp. 587-602.

Alvarado, S., J. Loaiza, y J. Patiño, (2011). “Movimiento juvenil indígena Álvaro Ulcué Chocué”. En H. Ospina, S. Alvarado, P. Botero, J. Patiño y M. Cardona (eds.) Experiencias de acción política con participación de jóvenes en Colombia: 17-42. Manizales: Centro de Estudios Avanzados en Niñez y Juventud de Cinde y Universidad de Manizales.

Balardini, Sergio (comp.) (2000). La participación social y política de los jóvenes en el horizonte del nuevo siglo. Buenos Aires: Clacso.

Barber, Benjamín (2000). Un lugar para todos. Barcelona: Paidós.

Beck, Ulrich (1999). Hijos de la libertad. Buenos Aires: Fondo de Cultura Económica.

Beck, Ulrich (1997). "La reinvención de la política: hacia una teoría de la modernización reflexiva". En Ulrich Beck, Anthony Giddens y Scott Lash. Modernización reflexiva. Política, tradición y estética en el orden social moderno: 13-74. Madrid: Alianza Editorial.

Benedicto, Jorge y Reinares, Fernando (1992). Las transformaciones de lo político. Madrid: Alianza Editorial.

Bianchi, Matías; Cristian León; y Antonella Perini (2017). Transformaciones de la participación política en América Latina. Buenos Aires: InnovaPolíticaLatam.

Cottet, Pablo (1994). "Los cambiantes discursos sobre la juventud". En 
Proposiciones, 24, Santiago: Ediciones SUR: 306-309.

Donoso, J., P. Moncagatta, A. Moscoso, S. Pachano, D. Montalvo, y E. Zechmeister, (2018). Cultura política de la democracia en Ecuador y en las Américas, 2016/17: Un estudio comparado sobre democracia y gobernabilidad. Quito: LAPOP y Vanderbilt University.

Donoso, J., D. Montalvo, D. Orcés, y E. Zechmeister, (2015). Cultura política de la democracia en Ecuador y en las Américas, 2014: Gobernabilidad democrática a través de 10 años del Barómetro de las Américas. Quito: LAPOP y Vanderbilt University.

Freidenberg, Flavia y Simón Pachano, (2015). El sistema político ecuatoriano. Quito: FLACSO Ecuador.

Jáuregui, Gurutz (1994). La democracia en la encrucijada, Barcelona: Anagrama.

Krauskopf, Dina (2013). Participación social y desarrollo en la adolescencia. Costa Rica: Fondo de Población de las Naciones Unidas.

Montero, José; Richard Gunther y Juan Linz, (2007). Partidos políticos: viejos conceptos y nuevos retos. Madrid: Editorial Trotta/Fundación Alfonso Martin Escudero.

O’Donell, Guillermo (2007). Disonancias. Críticas a la democracia. Buenos Aires: Prometeo Libros.

Ovejero, Félix (2003). "Las manifestaciones y la salud democrática". El País. Disponible en: https:/elpais.com/diario/2003/02/28/ opinion/1046386812_850215.html

Pachano, Simón (2006). Sistemas de representación política y elecciones, propuestas de reforma. Quito: FLACSO Ecuador. 
Primera Encuesta Nacional de Participación Ciudadana (2008). Quito: INEC.

Primera Encuesta Nacional sobre Jóvenes y Participación Política en Ecuador (2011). Quito: Ágora Democrática.

Puhle, Hans-Jurgen (2007). "Crisis y cambios de los partidos catch all". En Partidos políticos. Viejos conceptos y nuevos retos. José Montero, Richard Gunther y Juan Linz: 71-98. Madrid: Editorial Trotta/Fundación Alfonso Martin Escudero.

Putnam, Robert (2002). Solo en la bolera. Colapso y resurgimiento de la comunidad norteamericana. Barcelona: Galaxia Gutenberg / Círculo de Lectores.

Puyosa, Iria (2015). "Los movimientos sociales en red: del arranque emocional a la propagación de ideas de cambio político". En Revista Latinoamericana de Comunicación, 128: 197-214.

Ramoneda, Josep (1999). Después de la pasión política. Madrid: Taurus.

Sartori, Giovanni (1980). Partidos y sistemas de partidos. Madrid: Alianza Editorial.

Subirats, Joan (2011). Otra sociedad ¿Otra política? Barcelona: Icaria Editorial.

(1999). ¿Existe sociedad civil en España? Responsabilidades colectivas y valores públicos. Madrid: Fundación Encuentro.

Wattenberg, M. (2003). "Electoral turnout: The new generation gap". En British Elections \& Parties Review, 13(1), 159.

Wilkinson, Helen (1999). "Hijos de la libertad. ¿Surge una nueva ética de la responsabilidad individual y social?". En Hijos de la libertad. Ulrich 

ROTA?

Beck (comp.): 87-128. México: Fondo de Cultura Económica.

Worms, Jean Pierre (2003). "Viejos y nuevos vínculos cívicos en Francia”. En El declive del capital social: un estudio internacional sobre las sociedades y el sentido comunitario. Robert Putnam (ed.): 273-344. Barcelona: Galaxia Gutenberg / Círculo de Lectores.

Zubero, Imanol (2003) "Pasión Política". El País. Disponible en: https:// elpais.com/diario/2003/10/21/paisvasco/1066765203_850215.html 